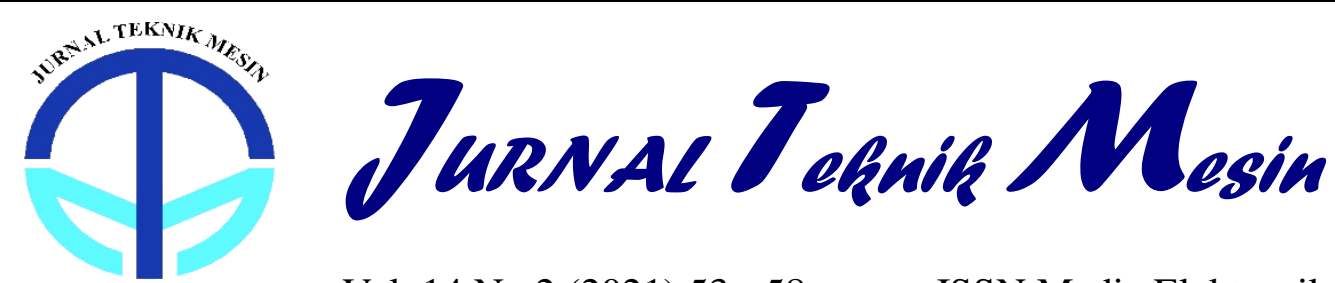

POLTTEKII NEGeri PADANG Vol. 14 No.2 (2021) 53 - 58

ISSN Media Elektronik: 2655-5670

\title{
Perhitungan Beban Statik pada Rangka Mesin Pengering Padi Menggunakan Baja AISI 1020
}

\author{
Iwan Nugraha Gusniar ${ }^{1}$, Aqsal Sheva Putra ${ }^{2}$ \\ ${ }^{1,2}$ Teknik Mesin, Fakultas Teknik, Universitas Singaperbangsa Karawang \\ ${ }^{1}$ iwannugrahajurnal@gmail.com ${ }^{2} 1810631150101 @$ student.unsika.ac.id
}

\begin{abstract}
In 2007 the government has targeted rice production to reach 61 million tons of dry milled grain (GKG) through the National Rice Production Improvement Program (P2BN). The role of mechanization engineering and technology is one of the efforts to create a better and more efficient agricultural system, including the provision of machinery and equipment, encouraging farmers to increase land productivity, overcoming transport problems and improving the quality of land and agricultural products. The rice dryer is one solution that can improve the production process in the agricultural sector, because the rice dryer does not depend on certain seasons but can be in all types of seasons. The frame of the rice dryer is a very important part to support the load of other parts on it, therefore the frame of the rice dryer must be given great attention. The purpose of this study was to determine the load received on the rice dryer and to choose the right material for the load. In this calculation, the shear force is $1372 \mathrm{~N}$, the value at the bending moment is $693.5 \mathrm{Nm}$ and the maximum shear stress is 343,000 $\mathrm{N} / \mathrm{mm}^{2}$. Because the maximum shear stress that occurs in the frame of the rice dryer is $343,000 \mathrm{~N} / \mathrm{mm}^{2}$ which is less than the allowable stress of the material $\left(351.57 \mathrm{~N} / \mathrm{mm}^{2}\right)$, the AISI 1020 material for the frame of the rice dryer is declared safe. AISI 1020 steel material was chosen because it is able to withstand the existing load and is suitable for use in the frame of the rice dryer
\end{abstract}

Keywords: Static Load, Rice Drying Machine, AISI 1020

\begin{abstract}
Abstrak
Pada tahun 2007 pemerintah telah mentargetkan produksi padi mencapai 61 juta ton gabah kering giling (GKG) melalui program Peningkatan Produksi Beras Nasional (P2BN). Peran keteknikan dan teknologi mekanisasi merupakan salah satu upaya untuk menciptakan sistem pertanian menjadi lebih baik serta efisien, mencakup pula penyediaan alsintan, mendorong petani meningkatkan produktivitas lahan, dan mengatasi masalah transport serta meningkatkan kualitas lahan maupun hasil pertanian. Mesin pengering padi merupakan salah satu solusi yang dapat meningkatkan proses produksi dalam sektor pertanian, karena mesin pengering padi tidak bergantung pada musim tertentu saja melainkan bisa di segala jenis musim. Rangka mesin pengering padi adalah bagian yang sangat penting untuk menopang beban bagian lain diatasnya, maka dari itu rangka mesin pengering padi harus sangat diperhatikan. Tujuan penelitian ini adalah untuk mengetahui beban yang diterima pada mesin pengering padi serta memilih material yang tepat untuk beban tersebut. Pada perhitungan ini didapat gaya geser sebesar $1372 \mathrm{~N}$, n ilai pada momen lentur sebesar 693,5 N.m dan nilai tegangan geser maksimum sebesar $343.000 \mathrm{~N} / \mathrm{mm}^{2}$. Dikarenakan tegangan geser maksimum yang terjadi rangka mesin pengering padi sebesar $343.000 \mathrm{~N} / \mathrm{mm}^{2} \mathrm{kurang}$ dari tegangan ijin material $\left(351,57 \mathrm{~N} / \mathrm{mm}^{2}\right)$, maka material AISI 1020 untuk rangka mesin pengering padi dinyatakan aman. Material baja AISI 1020 dipilih karena mampu menahan beban yang ada dan cocok digunakan untuk rangka mesin pengering padi
\end{abstract}

Kata kunci: Beban Statik, Mesin Pengering Padi, Baja AISI 1020

\section{Pendahuluan}

Perkembangan ilmu pengetahuan dan teknologi mengalami pertumbuhan yang sangat pesat. Sejak lahirnya revolusi industri manusia berlomba-lomba melakukan penelitian untuk menemukan teknologi yang bertujuan memudahkan kegiatan manusia seharihari, tanpa terkecuali perkembangan teknologi di bidang pertanian yang semakin lama mengalami kemajuan yang sangat pesat. Salah satunya pesatnya kemajuan ini dikarenakan pertumbuhan manusia yang semakin cepat, maka sektor pertanian dituntut untuk 
terus berkembang agar proses produksi bahan pangan yang mencukupi kebutuhan manusia yang juga semakin meningkat [1].

Konsumsi beras akan meningkat seiring laju pertumbuhan jumlah penduduk, namun terkadang petani kesulitan memenuhi permintaan tersebut karena dalam pengolahan padi sendiri diperlukan proses penjemuran terlebih dahulu pada gabah yang tidak dapat dilakukan apabila cuaca tidak mendukung. Pengeringan padi yang banyak memerlukan lahan yang luas untuk melakukan penjemuran dimana hal ini-sering menjadi kendala bagi para petani. Dengan perkembangan teknologi semakin cepat maka pada saat ini sudah tercipta mesin pengering padi. Penelitian ini bertujuan untuk mengetahui beban yang diterima oleh rangka mesin pengering padi serta memilih material yang tepat untuk beban tersebut.

Mesin pengering padi adalah mesin yang berfungsi untuk mengeringkan padi dimana sistem kerjanya menggunakan blower dan juga pemanas untuk menyalurkan udara panas yang akhirnya mengeringkan padi dalam proses pengeringannya padi ditempatkan dalam suatu bak penampungan dimana dibagian bawahnya diberi rongga untuk menyalurkan udara panas yang ditembakkan oleh blower.

Analisa efisiensi pengeringan alat pengering padi dimulai dari memasukan padi pada ruang pengering. Selanjutnya bahan bakar sekam padi dibakar di dalam tungku pembakaran. Udara panas hasil pembakaran dialirkan dengan blower menuju ruang pemanas dan udara panas akan mengalir menuju padi pada ruang pengering [8]. Kecepatan angin blower dan variasi jumlah pipa juga sangat berpengaruh terhadap energi yang diberikan udara, karena tinggi atau rendahnya energi yang diberikan udara ditentukan oleh kecepatan aliran udara dan jumlah pipa pemanas [9]

\section{Metode Penelitian}

Metode yang dilakukan untuk pengambilan data yaitu:

\subsection{Interview}

Metode ini dilakukan dengan cara melakukan interview dengan pihak $\mathrm{CV}$. $\mathrm{ABC}$ tentang cara perancangan, pembuatan, pengujian, sampai dengan pemanfaatan.

\subsection{Studi Pustaka}

Metode ini dilakukan dengan cara mengumpulkan literatur yang berkaitan dengan sistem blower, penghitungan dan pengujian.

\subsection{Dokumentasi}

Suatu pengumpulan data dengan cara melihat langsung sumber-sumber dokumen yang terkait.
Dengan arti lain bahwa dokumentasi sebagai pengambilan data melalui dokumen tertulis maupun elektronik sebagai mendukung kelengkapan data yang lain.

\section{Hasil dan Pembahasan}

\subsection{Rangka Mesin Pengering Padi}

Rangka atau frame adalah penopang terbesar dalam suatu kendaraan. Rangka tidak hanya berfungsi sebagai pondasi kendaraan tetapi juga sebagai tempat mounting komponen-komponen yang terdapat dalam suatu kendaraan seperti mesin, steer, pengereman, interior, dan komponen lainnya [2].

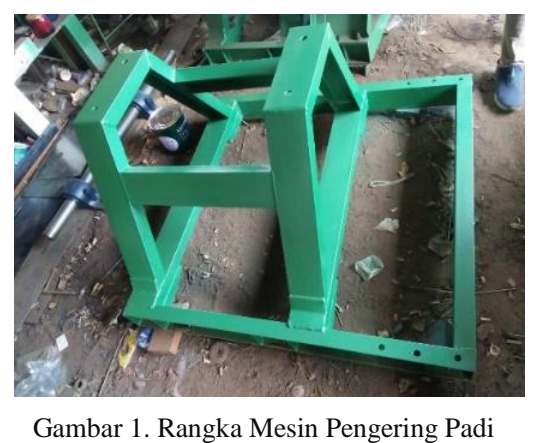

Rangka merupakan bagian mesin yang berfungsi sebagai pondasi suatu mesin yang menyangga komponen - komponen lain seperti motor, pemindah tenaga, serta bodi. Fungsi utama dari rangka adalah :

- Untuk mendukung gaya berat dari mesin

- Untuk menahan torsi dari mesin, kopling sentrifugal, aksi percepatan dan perlambatan, dan juga untuk menahan gaya torsi yang diakibatkan dari bentuk permukaan jalan.

- Untuk menahan beban kejut yang diakibatkan benturan dengan benda lain.

- Sebagai landasan untuk meletakan bodi kendaraan, mesin serta

- Kopling sentrifugal, tangki bahan bakar, tempat duduk penumpang.

Rangka batang yang dirancang untuk menumpu beban dan biasanya berupa struktur yang dikekang penuh dan stasioner. Rangka batang terdiri dari batang-batang lurus yang berhubungan pada titik kumpul yang terletak di ujung-ujung setiap batang [5].

Di atas rangka mesin pengering padi terdapat poros. Poros adalah suatu bagian stasioner yang berputar, biasanya berpenampang bulat dimana terpasang elemen-elemen seperti roda gigi (gear), Pulley, flywheel, engkol, sprocket dan elemen pemindah lainnya. Poros bisa menerima beban lentur, beban tarikan, beban tekan atau beban puntiran yang bekerja sendiri-sendiri atau berupa gabungan satu 
dengan lainnya [6].

\subsection{Baja AISI 1020}

Baja merupakan logam yang banyak digunakan dalam berbagai macam bidang, terutama di dalam bidang perindustrian. Pengaplikasian baja sangatlah beraneka ragam tergantung kebutuhan serta sifatsifat dari baja itu sendiri. Salah satu sifat baja yang penting ialah sifat mekanik. Sifat mekanik merupakan sifat-sifat yang berkaitan dengan daya kelakuan (behavior) terhadap beban mekanik. Sifat mekanik terdiri dari banyak macam kekuatan yaitu kekuatan (strength), ketangguhan (toughnes), kekerasan (hardness), keuletan (ductile) dan dengan modulus elastisitas dan ketahanan arus.

Baja AISI 1020 merupakan salah satu baja karbon rendah dengan unsur karbon $(1,40-1,70) \% \mathrm{Ni}$, $(0,90-1,40) \% \mathrm{Cr}$, dan $(0,20-0,30) \%$ Mo. Baja AISI 1020 setara dengan baja DIN CK22.C22, JIS S20C. Menurut standart AISI (American Iron and Steel Institute) dan DIN CK22.C22[11]. Komposisi kimia dari baja AISI 1020 dapat dilihat pada Tabel 1. di bawah ini.

\begin{tabular}{ccccccc}
\multicolumn{7}{c}{ Tabel 1. Komposisi Baja AISI 1020[11] } \\
\hline Kode & $\mathrm{C} \%$ & $\mathrm{Si} \%$ & $\mathrm{Mn} \%$ & $\mathrm{Mo} \%$ & $\mathrm{P} \%$ & $\mathrm{Cr} \%$ \\
\hline AISI & $0,20-$ & $0,15-$ & $0,50-$ & $0,20-$ & $0,03-$ & $0,90-$ \\
1020 & 0,30 & 0,35 & 0,70 & 0,30 & $\max$ & 1,40 \\
\hline
\end{tabular}

Baja AISI 1020 yang secara luas mudah tersedia sebagai gear, billet bar, batang forging, lembaran, tabung, dan kawat las. Aplikasi yang umum dari baja ini adalah untuk pembuatan baut, skrup, roda gigi, batang piston untuk mesin, dan komponen landing gear pesawat terbang. Baja AISI 1020 dengan kadar bajanya paduanya memungkinkan baja ini untuk dikeraskan dengan perlakuan panas. Salah satu perlakuan panas yang bisa digunakan pada baja ini yaitu proses hardening, dengan proses hardening baja AISI 1020 bisa mengalami perubahan sifat mekanik dengan variasi suhu austenisasi pada baja AISI 1020 yang di quenching dengan oli [3].

Bagian berikut ini akan membahas secara rinci tentang baja karbon AISI 1020.

\section{- Chemical Composition}

Komposisi kimia baja karbon AISI 1020 diuraikan dalam Tabel 2.

Tabel 2. Chemical Composition Baja AISI 1020 [3]

\begin{tabular}{lc}
\hline Element & Content $(\%)$ \\
\hline Manganese, Mn & $0,30-0,60$ \\
Carbon, C & $0,18-0,23$ \\
Sulfur, S & $0,05(\max )$ \\
Phosphorous, P & $0,04(\max )$ \\
Iron, Fe & Balance \\
\hline
\end{tabular}

\section{- Physical Properties}

Sifat fisik baja karbon AISI 1020 dijelaskan pada Tabel 3.

Tabel 3. Physical Properties Baja AISI 1020 [3]

\begin{tabular}{lcc}
\hline Properties & Metric & Imperiaal \\
\hline Thermal Exspansion & $7,87 \mathrm{~g} / \mathrm{cm}^{3}$ & $0,284 \mathrm{lb} / \mathrm{in}^{3}$ \\
\hline
\end{tabular}

\section{- Mechanical Properties}

Tabel 4. menunjukkan sifat mekanik baja karbon AISI 1020 canai dingin.

\begin{tabular}{lcc}
\multicolumn{3}{c}{ Tabel 4. Mechanical Properties Baja AISI 1020 [3] } \\
\hline Properties & Metric & Imperiaal \\
\hline Tensile Strength & $420 \mathrm{Mpa}$ & $60900 \mathrm{psi}$ \\
Yield Strength & $350 \mathrm{Mpa}$ & $50800 \mathrm{psi}$ \\
Modulus of elasticity & $205 \mathrm{Mpa}$ & $29700 \mathrm{ksi}$ \\
Shear Modulus & $80 \mathrm{Mpa}$ & $11600 \mathrm{ksi}$ \\
Poisson ratio & 0,29 & 0,29 \\
Elongation at break 50mm & $15 \%$ & $15 \%$ \\
Hardness, Brinell & 121 & 121 \\
Hardness, Knop & 140 & 140 \\
Hardness, Rockwell B & 68 & 68 \\
Hardness, Vickers & 126 & 126 \\
Machinability & 65 & 65 \\
\hline
\end{tabular}

\section{- Thermal Properties}

Sifat termal baja karbon AISI 1018 canai dingin diberikan dalam Tabel 5.

Tabel 5. Thermal Properties Baja AISI 1020 [3]

\begin{tabular}{lcc}
\hline Properties & Metric & Imperiaal \\
\hline Thermal Conductivity & $51,9 \mathrm{~W} / \mathrm{mK}$ & $360 \mathrm{BTU}$ in $? \mathrm{hr} . \mathrm{ft}^{2} .{ }^{\circ} \mathrm{f}$ \\
Thermal Exspansion & $11,7 \mathrm{um} ? \mathrm{~m}^{\circ} \mathrm{C}$ & $6,50 \mathrm{um} / \mathrm{m}^{\circ} \mathrm{C}$ \\
\hline
\end{tabular}

\subsection{Beban Statik}

Pada ilmu statika keseimbangan gaya-gaya didasarkan atas kondisi statik, dimana gaya-gaya tersebut tetap intensitasnya, tetap tempatnya dan tetap arah garis kerjanya. Gaya-gaya tersebut dikategorikan sebagai beban statik. kondisi tersebut akan berbeda dengan beban dinamik (Widodo, 2001).

Salah satu jenis kegagalan elemen mesin yaitu kegagalan akibat terjadinya deformasi plastik. Jenis kegagalan ini walaupun tidak membuat mesin secara keseluruhan berhenti berfungsi tetapi tetap bias mempengaruhi unjuk kerja elemen lainnya. Ada dua hal yang perlu diketahui dari kasus kegagalan deformasi plastik. Keduanya saling berkaitan dan saling menghasilkan sebab-akibat.

Batasan masalah dalam penelitian ini adalah hanya menghitung beban statiknya saja dan tidak menghitung beban dinamiknya, karena dalam rangka mesin pengering padi, gaya-gaya yang terjadi adalah gaya tetap atau tidak berubah digaris kerjanya. 


\subsection{Menghitung Gaya Geser Dan Momen Lentur}

Untuk mengetahui kegagalan dalam perancangan maka akan dilakukan analisa terhadap rangka mesin pengering padi meggunakan perhitungan manual.

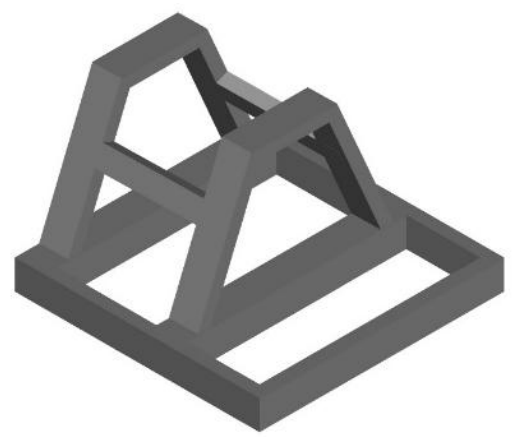

Gambar 2. Rangka Mesin Pengering Padi Menggunakan AutoCAD

Gaya geser merupakan gaya yang bekerja tegak lurus dengan bidang struktur atau vertikal. Tanda yang biasanya digunakan adalah $\mathrm{V}$.

Momen lentur merupakan Gaya putar yang terjadi diujung struktur (karena tumpuan) maupun di sepanjang bidang struktur. Tanda yang biasanya digunakan adalah $\mathrm{M}$.

Untuk mencari besar dari gaya geser dan momen lentur dapat dihitung dari persamaan keseimbangan, yaitu :

$$
\begin{aligned}
& \sum F=0 \\
& \sum M=0
\end{aligned}
$$

Selain perhitungan untuk mendapatkan besarnya gaya-gaya tersebut disini penting juga menentukan tanda atau positif/negatifnya dari gaya tersebut. Maka telah ditentukan perjanjian tanda untuk gaya geser $\mathrm{V}$ dan momen lentur $\mathrm{M}$ adalah sebagai berikut:

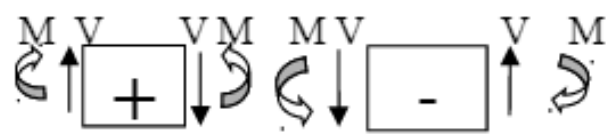

Gambar 3. Perjanjian tanda gaya geser dan momen lentur

Positive: gaya geser (v) searah jarum jam, Momen kopel menekan bagian atas

Negative: gaya geser (v) berlawanan jarum jam, Momen kopel menekan bagian bawah
$+7$

Deformasi akibat gaya

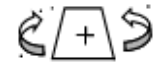

Deformasi akibat momen

Gambar 4. Deformasi akibat gaya dan momen

Salah satu jenis kegagalan elemen mesin yaitu kegagalan akibat terjadinya deformasi plastik. Selanjutnya dilakukan analisa gaya geser dan momen lentur pada rangka mesin pengering padi.

$$
\begin{aligned}
& \text { Diketahui : } \\
& \mathrm{m}=280 \mathrm{~kg} \\
& \mathrm{~L}=100 \mathrm{~cm}
\end{aligned}
$$

- Diagram Beban terdistribusi

A

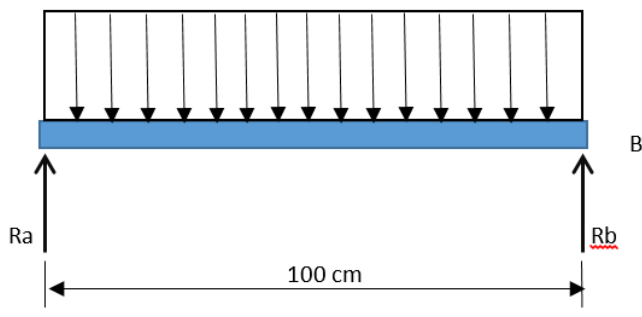

Gambar 5. Diagram Beban Terdistribusi

- Mencari Titik Pusat dari beban terdistribusi

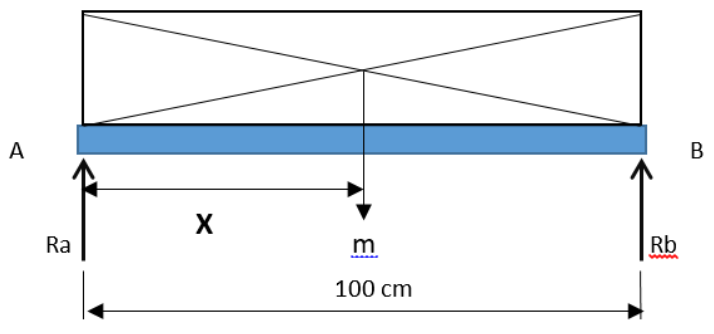

Gambar 6. Titik Pusat dari Beban Terdistribusi

Di dapat $\mathrm{x}$ atau titik pusat dari beban yang terdistribusi, pada beban yang terdistribusi sudah diketahui mempunyai panjang $100 \mathrm{~cm}$, jika $\mathrm{x}$ merupakan setengah dari panjang beban terdistribusi maka panjang $\mathrm{x}$ adalah $50 \mathrm{~cm}$

\section{- Menghitung Gaya Geser dan Momen Lentur}

Berikut ini merupakan Diagram Benda Bebas (DBB) pada rangka mesin pengering padi

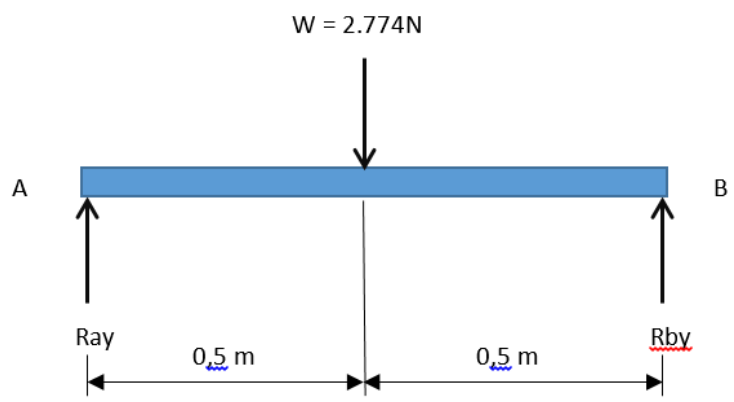


Gambar 7. Diagram Benda Bebas (DBB)

Ray = Reaksi pada Rangka depan

Rby = Reaksi pada Rangka belakang

$\mathrm{m}=$ Berat $(280 \mathrm{~kg})$

$\mathrm{W}=\mathrm{m} \times \mathrm{g}$

$\mathrm{W}=280 \mathrm{~kg} \times 9,8 \mathrm{~m} / \mathrm{s}^{2}=2.774 \mathrm{~N}$

Reaksi Tumpuan :

$\sum \mathrm{Fy}=0(\uparrow+)$

$$
\begin{aligned}
= & \text { Ray }+ \text { Rby }-\mathrm{W}=0 \\
= & \text { Ray }+ \text { Rby }-2.774 \mathrm{~N}=0 \\
& \text { Ray }+ \text { Rby }=2.774 \mathrm{~N}
\end{aligned}
$$$$
\sum M=0
$$

Rby $(0,5)-2.774(1)=0$

Rby $(0,5)=2,774$

Rby $=\frac{2.774}{0.5}=1.372 \mathrm{~N}$

Subtitusi Persamaan 3 dan 4

$$
\begin{aligned}
\text { Ray }+ \text { Rby } & =2.774 \mathrm{~N} \\
\text { Ray } & =2.774-1.372 \\
\text { Ray } & =1.372 \mathrm{~N}
\end{aligned}
$$

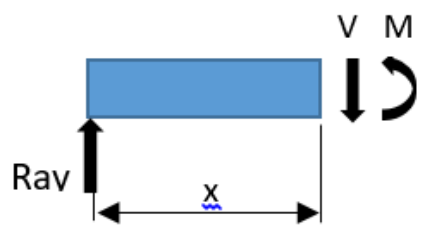

- $0 \leq \mathrm{x} \leq 0,5 \mathrm{~m}$

Gambar 8. Potongan $0 \leq \mathrm{x} \leq 0,5 \mathrm{~m}$

$$
\begin{aligned}
& \sum F_{y}=0 \\
& \text { Ray }+V_{1}=0 \\
& V_{1}=-1.372 \mathrm{~N} \\
& \begin{array}{c}
\sum M=0 \\
\text { Ray }+M_{1}=0, x=0 \\
M_{1}=-1.372 \mathrm{~N}(0) \\
M_{1}=0 \\
\text { Ray }+M_{1}=0, x=0,5 \mathrm{~m} \\
M_{1}=-1.372 \mathrm{~N}(0,5) \\
M_{1}=-693,5 \mathrm{Nm}
\end{array}
\end{aligned}
$$

- $0,5 \leq \mathrm{x} \leq 1 \mathrm{~m}$

$$
\begin{gathered}
\text { Gamba } \\
\mathrm{r} 9 . \\
\text { Potong } \\
\text { an } 0,5 \\
\leq \mathrm{x} \leq 1 \\
\mathrm{~m} \\
\sum F_{y} \\
=0 \\
-\mathrm{W} \\
+V_{2}
\end{gathered}
$$

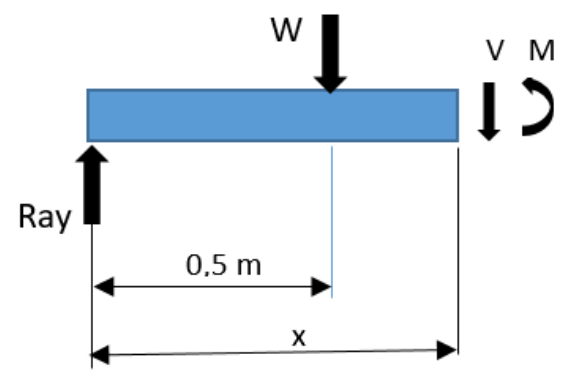

$$
\begin{aligned}
& =0 \\
& \qquad \begin{aligned}
V_{2} & =\mathrm{W}-R_{A y} \\
V_{2} & =2.774 \mathrm{~N}-1.372 \mathrm{~N} \\
V_{2} & =1.372 \mathrm{~N}
\end{aligned} \\
& \sum M=0 \quad \\
& R_{A y}(x)-\mathrm{W}(x-0,5)+M_{2}=0, x=1 \mathrm{~m} \\
& M_{2}=\mathrm{W}(x-0,5)-\operatorname{Ray}(x) \\
& M_{2}=2.774(1-0,5)-1.372(0,5) \\
& M_{2}=693,5 \mathrm{~mm}
\end{aligned}
$$

Dari perhitungan diatas diketahui bahwa:

$$
\mathrm{V} 1=-1.372 \mathrm{~N}(0<\mathrm{x}<0,5)
$$$$
\mathrm{V} 2=1.372 \mathrm{~N}(0,5<\mathrm{x}<1)
$$

Maka didapat diagram gaya gesernya adalah sebagai berikut:

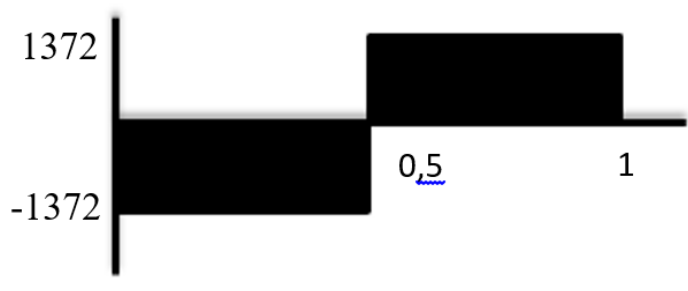

Gambar 10. Diagram Gaya Geser

Dari perhitungan sebelumnya diketahui bahwa:

$\mathrm{M} 1=-693,5 \mathrm{Nm}(\mathrm{x}=0,5 \mathrm{~m})$

$\mathrm{M} 2=693,5 \mathrm{Nm}(\mathrm{x}=1 \mathrm{~m})$

Maka didapat diagram momen lenturnyanya adalah sebagai berikut :

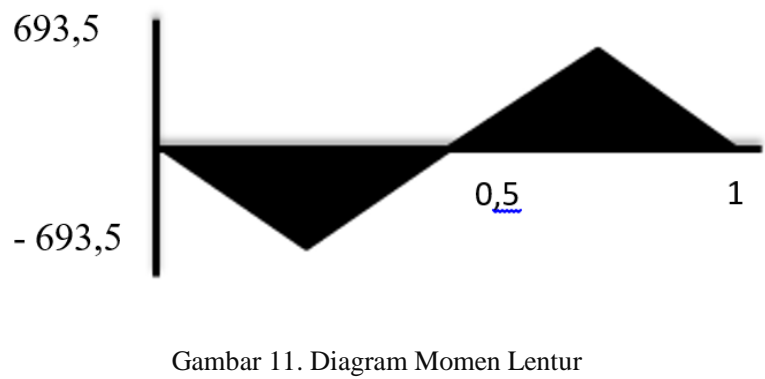

3.5 Menghitung momen inersia dan tegangan geser maksimum

- Menghitung momen inersia

Sebelum mendapatkan tegangan geser maksimum, kita harus mengetahui momen inersia dari rangka mesin pengering padi

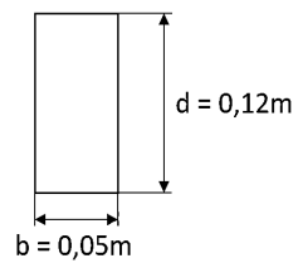


Gambar 12. Ukuran baja yang di pakai

Mencari momen inersia dengan menggunakan persamaan:

$$
\begin{aligned}
& I==\frac{1}{12} b d^{3} \\
& I=\frac{0,05(0,12)^{3}}{12} \\
& I=7,2 \times 10^{-6} \mathrm{~m}^{4}
\end{aligned}
$$

- Menghitung tegangan geser maksimum

Mencari tegangan geser maksimum dengan menggunakan persamaan:

$$
\begin{aligned}
\sigma \text { maks } & =\frac{3 \mathrm{Q}}{2 \mathrm{bd}} \\
\sigma \mathrm{maks} & =\frac{3(1.372)}{2(0,05)(0.12)} \\
\sigma \mathrm{maks} & =3,43 \times 10^{5} \mathrm{~N} / \mathrm{mm}^{2}
\end{aligned}
$$

Jadi, tegangan geser maksimum sebesar 343.000 $\mathrm{N} / \mathrm{mm}^{2}$.

\section{Kesimpulan}

Dari hasil analisa pada rangka mesin pengering padi yang dilakukan dengan menggunakan metode di atas menghasilkan beberapa kesimpulan, antara lain: Nilai pada gaya geser sebesar $1372 \mathrm{~N}$, nilai pada momen lentur sebesar 693,5 N.m dan nilai tegangan geser maksimum sebesar $343.000 \mathrm{~N} / \mathrm{mm}^{2}$. Karena tegangan geser maksimum yang terjadi rangka mesin pengering padi sebesar $343.000 \mathrm{~N} / \mathrm{mm}^{2}$ kurang dari tegangan ijin material $\left(351,57 \mathrm{~N} / \mathrm{mm}^{2}\right)$, maka material AISI 1020 untuk rangka mesin pengering padi dinyatakan aman. Material baja AISI 1020 dipilih karena mampu menahan beban yang ada dan cocok digunakan untuk rangka mesin pengering padi

\section{Daftar Rujukan}

[1] Kiki Suheiti., 2017. Alat Dan Mesin Pertanian Tepat Guna Untuk Tanaman Padi Dalam Mendukung Program Peningkatan Produksi Beras Nasional, Jurnal Badan Pengkajian Teknologi Pertanian (BPTP), Jambi Indonesia

[2] Francis. Vishal, Dkk., 2014. Structural Analysis of Ladder Chassis Frame for Jeep Using Ansys, India : International Journal of Modern Engineering Research

[3] F. a. S.M. Meyers., 2000. Manufacturing Facilities Design and Material Handling, 2nd ed, Prentice Hall, New Jersey.: Inc,

[4] Khurmi, R. S., \& Gupta, J. K. (1982). A Text Book Of Machine Design. Ram Nagar-New Delhi: Eurasia Publishing House.

[5] Ferdinand P. Beer., 1989. Mekanika Untuk Insinyur:STATIKA. $4^{\text {th }}$ ed. Jakarta: Erlangga

[6] Shigley, Joseph E., dan Larry D. Mitchell., 1983. Perencanaan Teknik Mesin. 4th ed (Gandhi Harahap, Penerjemah). Jakarta: Erlangga

[7] H. Sonawan,. 2014. Perancangan Elemen Mesin Edisi Revisi, Bandung: Alfabeta Cetakan Kedua

[8] Sutrisno dan Budi Raharjo. 2007. Rekayasa Mesin Pengering Padi Bahan Bakar Sekam Kapasitas 10 Ton Terintegrasi Pada Penggilingan Padi di Lahan Pasang Surut Sumatera Selatan. Jurnal Pembangunan Manusia Edisi 6

[9] Melkianus Rihi Kana1, Ben Vasco Tarigan1, Erick U. K. Maliwemu1., 2016. Pengaruh Kecepatan Angin Blower dan Jumlah Pipa Pemanas terhadap Laju Pengeringan pada Alat Pengering Padi Tipe Bed Dryer Berbahan Bakar Sekam Padi. LONTAR Jurnal Teknik Mesin Undana., 3(2), pp.29-34

[10]EP. Popov,. 1996. Mekanika Teknik (Mechanics Of Materials). Jakarta : Erlangga

[11]Muslih Nasution, Rini Halila Nasution., 2020. Analisa kekerasan dan struktur mikro baja aisi 1020 Terhadap perlakuan carburizing dengan Arang batok kelapa. Buletin utama teknik, 15(2), pp 165-173 